\title{
Correction to: Molecular Identification of a New Member of the Clover Proliferation Phytoplasma Group (16SrVI) Associated with Centaurea Solstitialis Virescence in Italy
}

\author{
Francesco Faggioli • Graziella Pasquini • Valentina Lumia • Luca Fornasari • \\ Gaetano Campobasso • Timothy L. Widmer • Paul C. Quimby Jr
}

Published online: 19 May 2020

(C) Koninklijke Nederlandse Planteziektenkundige Vereniging 2020

Correction to: European Journal of Plant Pathology 110, 353-360 (2004)

https://doi.org/10.1023/B:EJPP.0000

021059.85956.f2

The author Dr. L. Fornasari (Montpellier, France) has been added as the fourth author in the author list of [1]

[1] Faggioli, F., Pasquini, G., Lumia, V. et al. Molecular Identification of a New Member of the Clover Proliferation Phytoplasma Group (16SrVI) Associated with Centaurea Solstitialis Virescence in Italy.

The online version of the original article can be found at https://doi.org/10.1023/B:EJPP.0000021059.85956.f2

F. Faggioli · G. Pasquini · V. Lumia

Istituto Sperimentale per la Patologia Vegetale, Rome, Italy

L. Fornasari

Montpellier, France

\section{G. Campobasso}

European Biological Control Laboratory, USDA-ARS, Via Colle

Trugli No. 9, 00132 Rome, Italy

T. L. Widmer $(\bowtie) \cdot$ P. C. Quimby Jr,

European Biological Control Laboratory, USDA-ARS, Campus

International de Baillarguet, CS 90013 Montferrier sur Lez,

34988 St. Gely du Fesc, CEDEX, France

e-mail: tlwidmer@ars-ebcl.org 